\title{
A Meta-Analysis of Breakoff Rates in Mobile Web Surveys
}

\author{
Aigul Mavletova ${ }^{\star}$ and Mick P. Couper ${ }^{\dagger}$ \\ *National Research University Higher School of Economics, \\ Russia, amavletova@hse.ru, ${ }^{\dagger}$ Institute for Social Research, \\ University of Michigan, USA
}

\begin{abstract}
In this chapter, we conduct a meta-analysis of breakoff rates in mobile web surveys. We test whether the optimization of web surveys for mobile devices, invitation mode (SMS vs. email), survey length, expected duration stated in the survey invitation, survey design (scrolling vs. paging), prerecruitment, number of reminders, design complexity (grids, drop-down questions, sliders, images, progress indicator), incentives, opportunity to skip survey questions, and opportunity to select the preferred mode (PC or mobile web) have an effect on breakoffs. The meta-analysis is based on 14 studies (39 independent samples) conducted using online panels - probability-based and non-probability-based. We found that mobile optimized surveys, email invitations, shorter surveys, using prerecruitment, more reminders, a less complex design, and an opportunity to choose the preferred survey mode all decrease breakoff rates in mobile web surveys. No effect of a scrolling design, incentives, indicating expected duration in the invitation, and letting an opportunity to skip survey questions was found.
\end{abstract}

\section{Keywords}

mobile web surveys, breakoff rates, meta-analysis

\section{How to cite this book chapter:}

Mavletova, A and Couper, M P. 2015. A Meta-Analysis of Breakoff Rates in Mobile Web Surveys. In: Toninelli, D, Pinter, R \& de Pedraza, P (eds.) Mobile Research Methods: Opportunities and Challenges of Mobile Research Methodologies, Pp. 81-98. London: Ubiquity Press. DOI: http://dx.doi.org/10.5334/bar.f. License: CC-BY 4.0. 


\section{Introduction}

Breakoff rates in mobile web surveys are a key challenge for survey researchers. The research software Kinesis Survey Technologies (2013) reports that mobile breakoff rates in the surveys hosted on their SaaS infrastructure varied from $68 \%$ to $84 \%$ in the period of 2012-2013. These breakoff rates appear to be increasing in 2013 compared to 2012. They are also significantly higher than those on PC, which vary from $17 \%$ to $23 \%$. The overall percentage of mobile starts is $43 \%$ in 2013 (see Kinesis Survey Technologies 2013). The market research company Decipher reports about $20 \%$ of unintentional mobile respondents in their surveys and the average breakoff rate of $41 \%$ among smartphone respondents, compared to $24 \%$ among PC web respondents (Jue \& Luck 2014). This is on average three million partial mobile web interviews per year. Lightspeed research reports about 10 million annual breakoffs in the US, and a growing percentage of mobile web respondents among them (Johnson, Kelly \& Stevens 2012).

How can breakoff rates be decreased in mobile web surveys? In this chapter, based on a meta-analysis, we test if a variety of factors - including optimization of web surveys for mobile devices, invitation mode (SMS vs. email), survey length, indicating the expected duration of the survey in the invitation, survey design (scrolling vs. paging), prerecruitment, number of reminders, design complexity (grids, drop-down questions, sliders, images, progress indicator), incentives, an opportunity to skip survey questions, and an opportunity to select the preferred mode (PC or mobile web) - have an effect on breakoffs in mobile web surveys. The meta-analysis includes surveys conducted using online panels - both probability-based and non-probability-based volunteer panels.

\section{Literature review and hypotheses}

Galesic (2006) and Peytchev (2009) have explored the factors which can have an effect on breakoffs in PC web surveys. Peytchev (2009) found that presenting more questions on a single page and presenting questions with slider bars induce higher rates of breakoffs. Moreover, asking more burdensome questions, such as open-ended and long questions, as well as attitudinal questions, increased the likelihood of breakoffs on a page in PC web surveys. Galesic (2006) found that perceived interest and reported experienced burden can predict the likelihood of breakoffs in web surveys. Only a few experiments have measured factors which can affect breakoff rates in mobile web surveys (Mavletova \& Couper 2014a; Mavletova \& Couper 2014b). We have a number of expectations, based in part on these earlier experiments as well as on our assumptions.

The breakoff rates are higher in all types of mobile web surveys than in PC web surveys: this is the case for mobile-optimized (Baker-Prewitt 2013; 
Buskirk \& Andrus 2014; Lattery, Park Bartolone \& Saunders 2013; Mavletova 2013; Mavletova \& Couper 2013; Mavletova \& Couper 2014a; Mavletova \& Couper 2014b; Peterson et al. 2013), non-optimized (Bosnjak et al. 2013; Cunningham et al. 2013; Guidry 2012; Peterson 2012; Schmidt \& Wenzel 2013), and mobile-app surveys (Wells, Bailey \& Link 2013a; Wells, Bailey \& Link 2013b). However, some experiments found lower breakoff rates in mobile-optimized than non-optimized web surveys among mobile users (Baker-Prewitt 2013; Peterson et al. 2013; Stapleton 2013; for exception see McGeeney \& Marlar 2013). In the current meta-analysis, we expect to find that optimized mobile web surveys result in lower breakoff rates than non-optimized mobile web surveys.

Several papers have explored whether the invitation mode has an effect on breakoff rates in mobile web surveys. Maxl and his colleagues (2010) found that WAP (Wireless Application Protocol) push invitations, which display an alert invitation text on a mobile phone and direct respondents to a survey URL via a WAP browser, increased breakoff rates compared to SMS invitations, but resulted in similar participation rates. Mavletova and Couper (2014a) found that SMS invitations significantly increased both breakoff and participation rates relative to email invitations among mobile web respondents. Crawford and his colleagues (2013) also found that SMS slightly increased breakoff rates in a mobil-optimized web survey among students. We expect that email invitations decrease breakoff rates in mobile web surveys compared to SMS invitations.

Galesic and Bosnjak (2009) found that longer surveys produce higher breakoff rates in PC web surveys. Mavletova (2013) tested if survey length in mobile web surveys has an effect on breakoff rates. She compared surveys with expected durations of 5 and 15 minutes, which were completed on average within 10 and 29 minutes, respectively, and found slightly but not significantly higher breakoff rates in the longer survey. Pingatore and Seldin (2011) analyzed the location of breakoffs in a 100-item mobile web survey and found that most of the breakoffs occurred on the first screen - a pattern similar to PC web surveys. They suggest that survey length should not have a significant effect on breakoff rates in mobile web. Lattery, Park Bartolone, and Saunders (2013) found a larger effect of survey length on breakoff rates among mobile rather than PC web respondents in non-optimized surveys. We suggest that shorter surveys are associated with lower breakoff rates in mobile web surveys.

In addition, some surveys include the estimated survey duration in the invitation and some of them do not. We expect that indicating the survey duration decreases breakoff rates in mobile web surveys. When the expected survey duration is not mentioned in the invitation, the respondent's level of commitment may be lower, leading to a higher likelihood of breakoff, compared to when the survey duration is included (see Crawford, Couper \& Lamias 2001; Yan et al. 2010).

Although the AAPOR task force on mobile technologies suggests minimizing the use of a scrolling design in mobile web surveys by limiting the number of questions displayed on a single page to a maximum of two (Link et al. 2014), 
some experiments show that a scrolling design in mobile web surveys decreases breakoff rates. McGeeney and Marlar (2013) compared different scrolling versions (1 and 3 pages) in 7-item and 13-item mobile-optimized and non-optimized web surveys with paging versions. They found lower breakoff rates in the scrolling versions in which all items were presented on a single page. Mavletova and Couper (2014a) found lower breakoff rates in a 17-item scrolling version of a mobile-optimized survey presented on two pages than in a paging version. Respondents were initially invited to complete the survey via a cell phone and the device noncompliance rate (completing the survey via PC) was $14 \%$. However, the difference in breakoff rates between the paging and scrolling versions did not reach statistical significance $\left(\chi^{2}(1)=3.365, \mathrm{p}=0.067\right)$. In a subsequent experiment with a 30 -item survey they compared different scrolling versions with 5,15 , or all 30 questions presented on a page in a survey with or without user-controlled skips (Mavletova \& Couper 2014b). In the survey without skips the lowest breakoff rate was in the 30 -item per page (scrolling) condition. However, the difference was not statistically significant $\left(\chi^{2}(2)=3.611, p=0.164\right)$. No difference was found in the questionnaire with user-controlled skips. We expect that a scrolling design will produce lower breakoff rates than a paging design in mobile web surveys.

Some experiments conducted prerecruitment surveys to select those respondents who own cell phones with Internet access and who are willing to complete the main survey via a mobile device. Since even those respondents who own smartphones and use mobile Internet may not be willing to complete the survey via a mobile device, we suggest that using a prerecruitment survey decreases breakoff rates in mobile web surveys.

We also hypothesize that the number of reminders has an effect on breakoff rates. Reminders have an effect on response rates in PC web surveys (Brackbill et al. 2012; Cook, Heath \& Thompson 2000). We suggest that sending reminders decrease breakoff rates in mobile web surveys.

We expect that some survey design features increase the complexity of a mobile web survey, in terms of both added download time and added effort required on the part of respondents. Such design elements as grids, dropdown questions, images, slider bars, and progress indicators can increase breakoff rates. Jue (2012) found a higher breakoff rate on grid questions among mobile respondents in non-optimized web surveys. Peterson and his colleagues (2013) found slightly but not significantly higher breakoff rates in a mobile-optimized web survey with drop-down menus and a survey with slider bars compared to a basic mobile-optimized web survey with a simple interface. Mavletova (2013) found that about a third of respondents were unable to see an image in a mobile-optimized web survey. Villar, Callegaro and Yang (2013), in their meta-analysis of breakoff rates in web surveys, found that using a constant progress indicator does not decrease breakoffs. Overall, we suggest that less complex designs produce lower breakoff rates in mobile web surveys. 
Using incentives increases willingness to participate in web surveys (Göritz 2006). However, the effect depends on the size and type of incentives. Some researchers argue that incentives should be higher in mobile than PC web surveys to increase participation rates among mobile web users and compensate for additional survey burden. Wells, Bailey and Link (2013a; 2013b) offered mobile web respondents incentives that were five times higher than the usual incentives offered for completing a PC web survey. Johnson, Kelly and Stevens (2012) offered incentives for mobile web respondents that were three times higher than for PC web respondents in their experiment with a modular survey design. Buskirk and Andrus (2014) provided incentives for mobile web that were twice as high as that for a similar PC web survey. Due to experimental costs, Mavletova (2013) and Mavletova and Couper (2013; 2014a; 2014b) offered incentives for mobile web participation that were 40 percent lower than the usual incentives offered for PC web surveys in volunteer online panels. We expect that offering higher-than-usual incentives to panelists will decrease breakoff rates in mobile web surveys.

While we found no prior research on this topic, we also expect that an opportunity to skip survey questions and not answer all of them decreases survey burden. As a result, lower breakoff rates are expected compared to the condition where respondents are required to answer all questions.

Finally, we include two types of studies in the current meta-analysis - those studies which assign respondents to the mobile web survey mode without giving respondents an opportunity to choose the device (PC or mobile phone), and those studies which give participants an opportunity to select the preferred device. Assigning respondents to the mobile web survey mode means that respondents are explicitly asked to complete the survey via a mobile phone. We suggest that breakoff rates will be lower in the studies where respondents have a choice of device.

\section{Methods}

\section{Literature search}

Since research on mobile web surveys has only recently emerged and a number of studies have not (yet) been published, we included both published studies and unpublished conference presentations in our meta-analysis. We used the web survey methodology bibliographic database (http://www.websm.org) and searched for relevant papers from conferences such as those held by the AAPOR, General Online Research (GOR), European Survey Research Association (ESRA), ESOMAR, from the CASRO online research and digital research conferences, and from WebDataNet and the MESS (Measurement and Experimentation in the Social Sciences) workshops. The keywords used for searching were: 'mobile web', 'smartphone web', 'mobile web surveys', and 'smartphone 
web surveys'. We did not focus on tablet-only surveys; however, most of the papers included tablet users in the definition of mobile web users.

\section{Inclusion criteria}

A study was included in the meta-analysis if it met the following criteria: (1) it was conducted using online panels - both probability and non-probabilitybased; (2) respondents could either be assigned to mobile web surveys without having an opportunity to choose the device or be able to select their preferred device (PC web or mobile web); (3) mobile web surveys could be either browser-based or app-based; and (4) the study reported relevant statistics on breakoff rates and moderators. The search and inclusion criteria resulted in the inclusion of 14 studies with 39 independent samples (see a brief description of the studies and samples in Table 1).

\section{Moderators}

We included the moderators discussed in the hypotheses and literature review section in the model. Additionally, we planned to include such variables as the country of data collection, the average number of items presented on a page, the panel type (probability or non-probability), and the year of data collection. However, due to higher multicollinearity (VIF more than 15) these variables were excluded from the meta-analysis. The other moderators included in the model had a VIF lower than 5, except for survey length. Survey length had a VIF of 5.6. Socio-demographic variables were not included in the current meta-analysis, since not all experiments reported this information.

\begin{tabular}{|l|l|l|}
\hline № & \multicolumn{1}{|c|}{ Study } & \multicolumn{1}{c|}{ Breakoff Rates (mobile devices only) } \\
\hline 1 & $\begin{array}{l}\text { Baker-Prewitt } \\
2013\end{array}$ & $\begin{array}{l}13 \% \text { in a mobile optimized survey, } \\
18 \% \text { in a non-optimized survey }\end{array}$ \\
\hline 2 & $\begin{array}{l}\text { Buskirk \& } \\
\text { Andrus 2014 }\end{array}$ & $30.9 \%$ in a mobile optimized survey \\
\hline 3 & $\begin{array}{l}\text { de Bruijne \& } \\
\text { Wijnant 2013 }\end{array}$ & $5.5 \%$ in a mobile optimized survey \\
\hline 4 & $\begin{array}{l}\text { Lattery, Park } \\
\text { Bartolone \& } \\
\text { Saunders 2013 }\end{array}$ & $20.9 \%$ in a mobile optimized survey \\
\hline 5 & $\begin{array}{l}\text { Mavletova 2013 } \\
16.3 \% \text { in a shorter survey, } \\
20.3 \% \text { in a longer survey }\end{array}$ \\
\hline 6 & $\begin{array}{l}\text { Mavletova \& } \\
\text { Couper 2013 }\end{array}$ & $\begin{array}{l}13.6 \% \text { in the first wave, } \\
12.7 \% \text { in the second wave }\end{array}$ \\
\hline
\end{tabular}




\begin{tabular}{|c|c|c|}
\hline № & Study & Breakoff Rates (mobile devices only) \\
\hline 7 & $\begin{array}{l}\text { Mavletova \& } \\
\text { Couper 2014a }\end{array}$ & $\begin{array}{l}11.5 \% \text { in the paging design in SMS invitation, } \\
10.4 \% \text { in the scrolling design in SMS invitation, } \\
7.5 \% \text { in the paging design in email invitation, } \\
3.1 \% \text { in the scrolling design in email invitation }\end{array}$ \\
\hline 8 & $\begin{array}{l}\text { Mavletova \& } \\
\text { Couper } 2014 b\end{array}$ & $\begin{array}{l}12.2 \% \text { in the scrolling design with one page, } \\
13.0 \% \text { in the scrolling design chunked into two pages, } \\
14.9 \% \text { in the scrolling design chunked into three pages }\end{array}$ \\
\hline 9 & $\begin{array}{l}\text { McGeeney \& } \\
\text { Marlar } 2013^{25}\end{array}$ & $\begin{array}{l}2.7 \% \text { in a non-optimized } 13 \text {-item survey with a scrolling } \\
\text { design chunked into three pages, } \\
1.0 \% \text { in a non-optimized } 7 \text {-item survey with a paging design, } \\
1.4 \% \text { in a non-optimized } 13 \text {-item survey with a paging } \\
\text { design, } \\
0.9 \% \text { in a non-optimized } 7 \text {-item survey with a scrolling } \\
\text { design with one page, } \\
0.9 \% \text { in an optimized } 13 \text {-item survey with a scrolling design } \\
\text { chunked into three pages, } \\
0.4 \% \text { in an optimized } 7 \text {-item survey with a paging design, } \\
2.4 \% \text { in an optimized } 13 \text {-item survey with a paging design, } \\
1.4 \% \text { in a non-optimized } 13 \text {-item survey with a scrolling } \\
\text { design with one page, } \\
0.5 \% \text { in an optimized } 13 \text {-item survey with a scrolling design } \\
\text { with one page }\end{array}$ \\
\hline 10 & Pearson 2012 & $22.2 \%$ in a mobile optimized web survey \\
\hline 11 & $\begin{array}{l}\text { Peterson et al. } \\
2013\end{array}$ & $\begin{array}{l}13 \% \text { in a non-optimized mobile web survey, } \\
5 \% \text { in an optimized mobile web survey, } \\
4 \% \text { in an optimized mobile web survey with numeric input, } \\
7 \% \text { in an optimized mobile web survey with sliders, } \\
5 \% \text { in an optimized mobile web survey with drop-down } \\
\text { questions }\end{array}$ \\
\hline 12 & Stapleton 2013 & $\begin{array}{l}8.2 \% \text { in a longer mobile optimized web survey with progress } \\
\text { indicator, } \\
10.2 \% \text { in a longer mobile optimized web survey with progress } \\
\text { indicator and drop-down questions, } \\
6.3 \% \text { in a shorter mobile optimized web survey with progress } \\
\text { indicator, } \\
7.8 \% \text { in a shorter mobile optimized web survey with progress } \\
\text { indicator and drop-down questions, } \\
15.9 \% \text { in a non-optimized web survey }\end{array}$ \\
\hline 13 & $\begin{array}{l}\text { Toepoel \& } \\
\text { Lugtig } 2014 \\
\end{array}$ & $1.4 \%$ in a mobile optimized web survey \\
\hline 14 & $\begin{array}{l}\text { Wells, Bailey \& } \\
\text { Link 2013b }\end{array}$ & $\begin{array}{l}3.7 \% \text { in a mobile-app survey, } \\
5.3 \% \text { in a in a non-optimized web survey }\end{array}$ \\
\hline
\end{tabular}

Table 1: Description of the Studies.

${ }^{25}$ A non-optimized 7-item web survey with a scrolling design with one page is not included in the analysis, since no breakoffs were found in that condition. 
Moderators were included using the following code: mobile-optimized web survey = 1 and non-optimized web survey $=0$; email invitation $=1$ and SMS invitation $=0$; survey length varying from 2 to 30 minutes; expected duration is included in the invitation $=1$, expected duration is not included $=0$; scrolling design $=1$, paging design $=0$; prerecruitment $=1$, no prerecruitment $=$ 0 ; number of reminders varying from 0 to 2 ; survey design complexity varying from $0.2=$ one out five design elements to $1=$ all five elements (grids, drop-down questions, images, slider bars, and progress indicator); incentives varying from $0=$ no incentives to $5=$ incentives five times higher than typical incentives for PC web surveys; survey questions obligatory to complete $=1$ and respondents have an opportunity to skip some questions $=0$; and surveys assigned respondents to mobile web mode $=1$ and respondents could select the preferred mode $=0$.

\section{Sample characteristics}

The current meta-analysis includes 39 independent samples, with the breakoff rates varying from $0.9 \%$ to $30.9 \%$ and with a total number of 4,209 breakoffs among 34,589 participants who started the surveys. On average, 2.6\% of participants were tablet users. About two thirds of the surveys are from the United States (65\%), 28\% are from Russia, and 7\% from European countries. The surveys were conducted between 2010 and 2013. More than a half (54\%) of the studies assigned respondents to a mobile web survey without giving them an opportunity to select their preferred mode. Despite this, some respondents completed the survey in the PC web survey mode in these latter experimental studies. Breakoff rates were calculated based only on mobile web respondents in our meta-analysis. About a third of the surveys were conducted using probability-based panels.

\section{Meta-analytic procedure}

Since breakoff rates (BR) are calculated as the proportion of those who broke off out of all those who started the survey, the proportions can be used as the effect size. Lipsey and Wilson (2001) suggest that using proportions less than 0.20 underestimates the confidence intervals of mean proportions and overestimates the heterogeneity of the proportions across surveys. Almost all breakoff rates in the current meta-analysis are lower than 0.20 . In that case the proportion is transformed into log transformed proportion: $\ln \left(\frac{B R}{1-B R}\right)$. The effect sizes are reported in log transformed proportions and odds ratios (OR, see Table 2). We used the 'metafor' package - a meta-analysis package in $\mathrm{R}$ - for data analysis (http://www.metafor-project.org; Chen \& Peace 2013). 


\section{Results}

Influential case diagnostics (Viechtbauer 2010; Viechtbauer \& Cheung 2010) show that three surveys are influential outliers, since the Cook's distances, standardized residuals, and DFFITS values of these surveys are large. To reduce the impact of these studies (Buskirk \& Andrus 2014; Pearson 2012; Wells, Bailey \& Link 2013b) we truncated the effect size to the upper or lower bound of the $90 \%$ confidence interval of the effect size calculated without these outliers (see Gnambs 2013). There was also an outlier in the sample size (a non-optimized web survey in Stapleton 2013). We truncated it to the largest sample size of the remaining surveys.

A random-effects model of breakoff rates shows that the average breakoff rate in mobile web surveys is $6.6 \%$ with the confidence interval of $5.3 \%$ to $8.2 \%$ (see log transformed proportions in forest plot in Figure 1). The test for heterogeneity $(\mathrm{Q}(38)=628.78, \mathrm{p}<0.001)$ is statistically significant, which means that the studies included in the analysis are heterogeneous. The percentage of total variation due to variation between studies is very high $\left(\mathrm{I}^{2}=97.7 \%\right) .95 \%$ confidence interval in brackets.

A mixed-effects meta-regression explains the $\mathrm{R}^{2}=0.86$ of the random between-study variance $\left(\tau^{2}\right)$. As expected, mobile-optimized surveys, email invitations, shorter surveys, using prerecruitment, a larger number of reminders, a less complex design, and an opportunity to choose the preferred survey mode (PC web or mobile web) are significantly associated with lower breakoff rates in mobile web surveys (see Table 2).

Mobile-optimized web surveys decrease the odds of breakoffs among mobile respondents by $0.71(\mathrm{p}<0.01$, see Table 2$)$ compared to non-optimized web surveys. Email invitations decrease the odds of breakoffs by $0.47(\mathrm{p}<0.001)$ compared to SMS invitations. Prerecruitment decreases the odds of breakoffs by $0.68(\mathrm{p}<0.05)$. Sending a larger number of reminders also decreases the odds of breakoffs $(\mathrm{p}<0.01)$. Sending one reminder decreases the odds of breakoffs by 0.85 , two reminders by 0.54 , and three reminders by 0.39 compared to sending only the invitation. Including such design elements as grids, drop-down questions, images, slider bars, and progress indicators increases the probability of breakoffs $(\mathrm{p}<0.001)$. Including one complex design element increases the odds of breakoffs by 1.30, and including all five elements by 1.91, compared to the condition without any of these elements. If respondents have an opportunity to select their preferred mode the odds of breakoff rates are decreased by $0.62(\mathrm{p}<0.05)$ compared to the surveys in which respondents are initially assigned to a mobile web survey mode. Survey length did not reach statistical significance $(\mathrm{p}=0.07)$. However, it explains the largest proportion of the between-study variance $\left(R^{2}=0.45\right)$. A 10 -minute survey increases the odds of breakoffs by 1.09 and a 30-minute survey by 1.42 compared to a 5 -minute mobile web survey. 


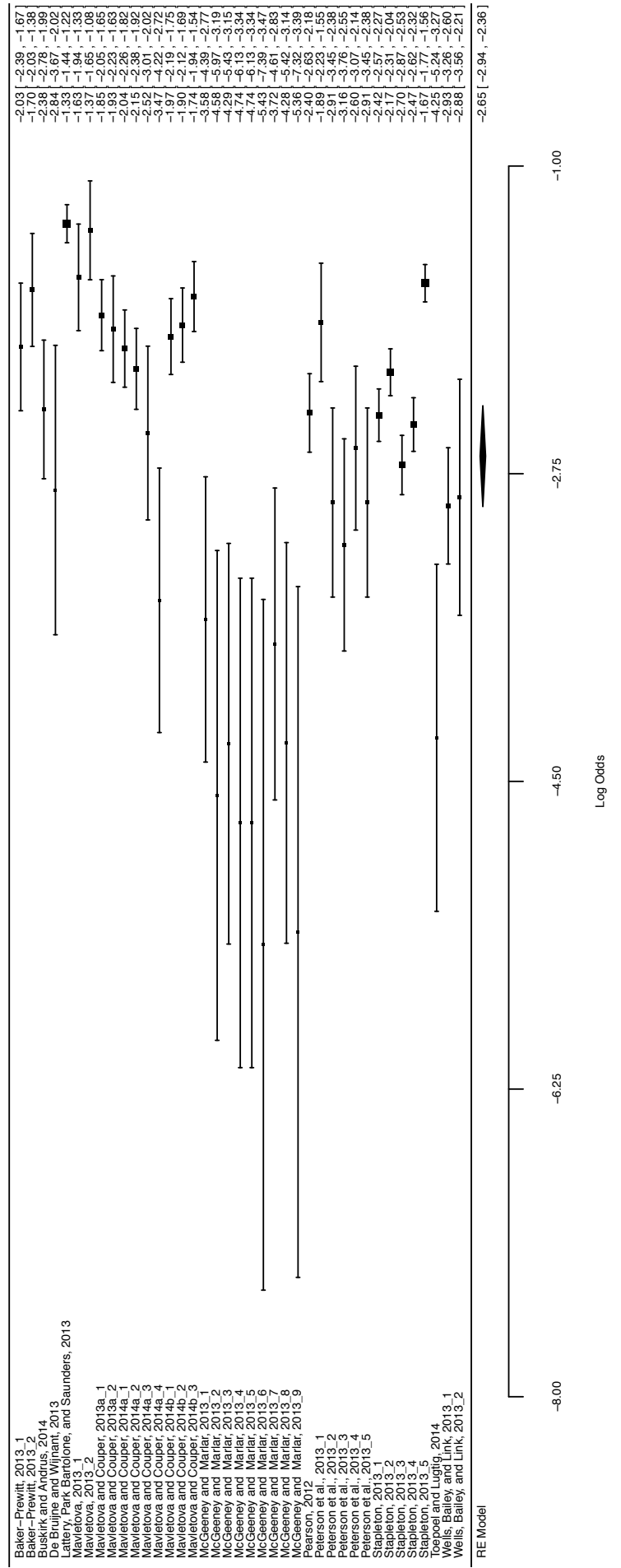

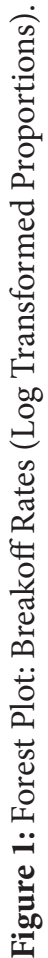




\begin{tabular}{|c|c|c|c|}
\hline Factors & $\begin{array}{c}\text { Lower breakoff } \\
\text { rates in mobile } \\
\text { web surveys } \\
\text { are expected: }\end{array}$ & $\begin{array}{l}\text { Supported/ } \\
\text { not } \\
\text { supported }\end{array}$ & $\begin{array}{l}\text { Effect size: } \log \text { transformed } \\
\text { proportions and the odds ratios }\end{array}$ \\
\hline $\begin{array}{l}\text { Optimization } \\
\text { for mobile } \\
\text { devices }\end{array}$ & $\begin{array}{l}\text { in optimized } \\
\text { mobile web } \\
\text { surveys }\end{array}$ & supported & $\begin{array}{l}\ln \left(\frac{B R}{1-B R}\right)=-0.60 * * \\
(-0.98,-0.21) \\
\text { OR }=0.71(0.54,0.89)\end{array}$ \\
\hline $\begin{array}{l}\text { Invitation } \\
\text { mode }\end{array}$ & $\begin{array}{l}\text { in email than in } \\
\text { SMS invitation }\end{array}$ & supported & $\begin{array}{l}\ln \left(\frac{B R}{1-B R}\right)=-1.18 \text { ***} \\
(-1.70,-0.67) \\
\mathrm{OR}=0.47(0.31,0.68)\end{array}$ \\
\hline Survey length & $\begin{array}{l}\text { in shorter } \\
\text { surveys }\end{array}$ & $\begin{array}{l}\text { supported } \\
(\mathrm{p}=0.07)\end{array}$ & $\begin{array}{l}\ln \left(\frac{B R}{1-B R}\right)=0.04 \\
(0.00,0.09)+ \\
\text { OR }(10 \text { to } 5 \text { min })=1.09(0.99, \\
1.16) \\
\text { OR }(20 \text { to } 5 \text { minutes })=1.27 \\
(0.97,1.40) \\
\text { OR }(30 \text { to } 5 \text { minutes })=1.42(0.95, \\
1.53)\end{array}$ \\
\hline $\begin{array}{l}\text { Including } \\
\text { expected } \\
\text { survey } \\
\text { duration in the } \\
\text { invitation }\end{array}$ & $\begin{array}{l}\text { in surveys } \\
\text { which include } \\
\text { the expected } \\
\text { duration in the } \\
\text { invitation }\end{array}$ & $\begin{array}{l}\text { not } \\
\text { supported }\end{array}$ & $\begin{array}{l}\ln \left(\frac{B R}{1-B R}\right)=-0.38 \\
(-1.08,0.32) \\
\text { n.s. }\end{array}$ \\
\hline Survey design & $\begin{array}{l}\text { in a scrolling } \\
\text { than in a } \\
\text { paging design }\end{array}$ & $\begin{array}{l}\text { not } \\
\text { supported }\end{array}$ & $\begin{array}{l}\ln \left(\frac{B R}{1-B R}\right)=-0.12 \\
(-0.61,0.37) \\
\text { n.s. }\end{array}$ \\
\hline Prerecruitment & $\begin{array}{l}\text { in surveys } \\
\text { with a } \\
\text { prerecruitment } \\
\text { phase }\end{array}$ & supported & $\begin{array}{l}\ln \left(\frac{B R}{1-B R}\right)=-0.67^{*} \\
(-1.20,-0.14) \\
\text { OR }=0.68(0.46,0.93)\end{array}$ \\
\hline
\end{tabular}

(Continued) 


\begin{tabular}{|c|c|c|c|}
\hline Factors & $\begin{array}{l}\text { Lower breakoff } \\
\text { rates in mobile } \\
\text { web surveys } \\
\text { are expected: }\end{array}$ & $\begin{array}{l}\text { Supported/ } \\
\text { not } \\
\text { supported }\end{array}$ & $\begin{array}{l}\text { Effect size: log transformed } \\
\text { proportions and the odds ratios }\end{array}$ \\
\hline $\begin{array}{l}\text { Number of } \\
\text { reminders }\end{array}$ & $\begin{array}{l}\text { in surveys with } \\
\text { a larger number } \\
\text { of reminders }\end{array}$ & supported & $\begin{array}{l}\ln \left(\frac{B R}{1-B R}\right)=-0.31^{* *} \\
(-0.53,-0.09) \\
\text { OR }(1 \text { to } 0 \text { reminders })=0.85 \\
(0.74,0.96) \\
\text { OR }(2 \text { to } 0 \text { reminders })=0.54 \\
(0.35,0.84) \\
\text { OR }(3 \text { to } 0 \text { reminders })=0.39 \\
(0.20,0.77)\end{array}$ \\
\hline $\begin{array}{l}\text { Survey design } \\
\text { complexity } \\
\text { (grids, } \\
\text { drop-down } \\
\text { questions, } \\
\text { images, } \\
\text { slider bars, } \\
\text { and progress } \\
\text { indicators) }\end{array}$ & $\begin{array}{l}\text { in surveys with } \\
\text { a lower design } \\
\text { complexity }\end{array}$ & supported & $\begin{array}{l}\ln \left(\frac{B R}{1-B R}\right)=3.06^{* * *} \\
\text { OR }(1 \text { to } 0 \text { elements })=1.30 \\
(1.20,1.39) \\
\text { OR }(5 \text { to } 0 \text { elements })=1.91 \\
(1.76,1.97)\end{array}$ \\
\hline Incentives & $\begin{array}{l}\text { in surveys } \\
\text { with higher } \\
\text { incentives }\end{array}$ & $\begin{array}{l}\text { not } \\
\text { supported }\end{array}$ & $\begin{array}{l}\ln \left(\frac{B R}{1-B R}\right)=0.11 \\
(-0.10,0.32) \\
\text { n.s. }\end{array}$ \\
\hline $\begin{array}{l}\text { Opportunity } \\
\text { to skip survey } \\
\text { questions }\end{array}$ & $\begin{array}{l}\text { in surveys with } \\
\text { an opportunity } \\
\text { to skip survey } \\
\text { questions }\end{array}$ & $\begin{array}{l}\text { not } \\
\text { supported }\end{array}$ & $\begin{array}{l}\ln \left(\frac{B R}{1-B R}\right)=0.14 \\
(0.53,0.64) \\
\text { n.s. }\end{array}$ \\
\hline $\begin{array}{l}\text { Assigned to } \\
\text { mobile web or } \\
\text { could choose } \\
\text { the mode }\end{array}$ & $\begin{array}{l}\text { in surveys with } \\
\text { an opportunity } \\
\text { to select the } \\
\text { preferred mode } \\
\text { (PC web or } \\
\text { mobile web) }\end{array}$ & supported & $\begin{array}{l}\ln \left(\frac{B R}{1-B R}\right)=-0.81^{*} \\
(-1.55,-0.06) \\
\text { OR }=0.62(0.35,0.97)\end{array}$ \\
\hline
\end{tabular}

Table 2: Hypotheses and Effect Sizes.

${ }^{* * *} \mathrm{p}<0.001,{ }^{* *} \mathrm{p}<0.01,{ }^{*} \mathrm{p}<0.05,+\mathrm{p}=0.07 ; 95 \%$ confidence interval in parentheses 
No effect of a scrolling design, incentives, indicating the expected duration of the survey in the invitation, and an opportunity to skip survey questions was found.

\section{Discussion and conclusion}

What are the implications of the meta-analysis presented here? It shows the importance of optimizing web surveys for mobile devices to minimize breakoffs among mobile respondents. While this might be self-evident, using less complex design elements should also be considered. Using such elements as grids, sliders, and images is associated with higher breakoffs among mobile respondents. Shorter surveys are more efficient. There is research evidence that completing a survey on a smartphone takes more time than completing a survey on a PC (de Bruijne \& Wijnant 2013; Gummer \& Roßmann 2014; Mavletova 2013; Mavletova \& Couper 2013; Pearson 2012; Peterson et al. 2013; Wells, Bailey \& Link 2013a). One possible solution for mobile web surveys can be to use modular (or chunked) surveys. Johnson, Kelly and Stevens (2012) proposed using app-based modular surveys, which chunk a long web survey into shorter 5-10-minute surveys for mobile respondents. They found that while the breakoff rates in a full PC web survey was $6 \%$, all mobile respondents who started completing the modules in a mobile application finished all five modules. Moreover, there was a lower perceived survey burden among mobile than PC web respondents in terms of the subjective evaluation of the survey length (more respondents stated that the survey was shorter than expected). However, in their following experiment Kelly, Johnson and Stevens (2013) found slightly higher breakoff rates in a modular mobile survey than in a PC web survey. Siluk, Johnson and Tarraf (2013) also found higher breakoff rates in a modular mobile web survey (25\%) than in a full mobile (8\%) or in a full PC web survey (11\%). It is worth including modular mobile web surveys in a future meta-analysis to measure whether it decreases breakoff rates compared to a full mobile web survey.

We found that sending a larger number of reminders, using prerecruitment, giving an opportunity for respondents to select the preferred mode (vs. assignment to mobile web survey mode), and sending email (vs. SMS) invitations are associated with lower breakoff rates in mobile web surveys. There is some research evidence, however, that SMS invitations increase participation rates among mobile web respondents compared to PC web respondents (Crawford et al. 2013; Mavletova \& Couper 2014a).

Contrary to expectations, no effect of the scrolling design was found. This can be due to limitations in the current meta-analysis. Only three studies included in the current analysis (Mavletova \& Couper 2014a; Mavletova \& Couper 2014b; McGeeney \& Marlar 2013) tested scrolling versions. McGeeney and Marlar (2013) had a small number of mobile respondents in their survey, with only a few breakoffs in each of the scrolling and paging versions. Mavletova 
and Couper (2014a; 2014b) found slightly (but not significantly) lower breakoff rates for the scrolling design in two studies. To measure the effect of this design feature in future meta-analyses, it is worth including a larger number of experiments and measuring odds ratios of breakoff rates between the scrolling and paging designs in mobile web surveys.

We found no effect of higher incentives on breakoff rates in mobile web surveys. Despite these results we still suggest that higher incentives can both increase participation rates and decrease breakoff rates in mobile web surveys. However, to our knowledge, no experiments comparing the effect of different incentives have been conducted among mobile web samples.

The current meta-analysis of breakoff rates in mobile web surveys should be considered as preliminary. It is based on two types of studies, those which assign respondents to mobile web mode and those in which respondents could select the mode they prefer. Since there is a self-selection bias in the latter studies, future meta-analyses should be restricted, as a sufficient number of studies become available, to those studies which randomly assign respondents to a PC or mobile web mode. The current analysis did not measure the effect of app-based versus mobile-browser-based surveys on breakoff rates, since only 1 study among the 14 had an app-based condition (Wells, Bailey \& Link 2013b). We hypothesize that app-based mobile surveys may have lower breakoff rates because there is no need for a persistent Internet connection. However, they may have higher nonresponse rates, because of the need to install the app. In a future meta-analysis, it is worth comparing these two types of surveys. We also did not measure the single effect of different design elements (grids, drop-down questions, sliders, images, progress indicators) on breakoff rates. In a future meta-analysis it is worth exploring the effect of each survey element and taking into consideration more details for each, such as the number of grids, sliders, and images in the survey, the number of items in the grids, etc. Due to higher multicollinearity, such variables as the country of data collection, number of survey items presented on a single page, panel type (probability or non-probability), and year of data collection were not included in the analysis. We suggest that these variables could also have explained some proportion of the random between-study variance. Though the survey length explained the largest proportion of the between-study variance, it did not reach statistical significance $(p=0.07)$. This could be due to higher multicollinearity. In a future meta-analysis which would include a larger number of studies, we would expect to find effects of survey length on breakoff rates.

In spite of these limitations, the current meta-analysis shows that researchers should take into consideration some basic survey features such as mobile optimization, survey length, and questionnaire design elements while designing surveys for both PC and mobile web respondents. These design elements have an effect on breakoffs (as we have shown here), but also on measurement error (as several papers have shown, e.g., McClain \& Crawford 2013; Peterson et. al. 2013). 


\section{Acknowledgement of funding sources}

This work was supported by the research grant [13-05-0035] provided to the first author under 'The National Research University Higher School of Economics Academic Fund Program' in 2013-2014.

\section{References}

Baker-Prewitt, J. (2013, March). Mobile research risk: What happens to data quality when respondents use a mobile device for a survey designed for a PC. Paper presented at the CASRO Online Research Conference, San Francisco, USA.*

Brackbill, R., Yu, S., Walker, D., Turner, L., Miller, S., Farfel, M., \& Stellman, S. (2012, May). Multiple email reminders and response rate for an internet based survey. Paper presented at the AAPOR Annual Conference, Orlando, FL, USA.

Buskirk, T.D., \& Andrus, C. (2014). Making mobile browser surveys smarter: results from a randomized experiment comparing online surveys completed via computer or smartphone. Field Methods, published online before print 14 April 2014. DOI: http://dx.doi.org/10.1177/1525822X14526146*

Chen, D.-G., \& Peace, K.E. (2013). Applied meta-analysis. Boca Raton, FL: R. Taylor \& Francis Group.

Cook, C., Heath, F., \& Thompson, R.L. (2000). A meta-analysis of response rates in web- or internet-based surveys. Educational and Psychological Measurement, 60(6), 821-836. DOI: http://dx.doi.org/10.1177/00131640021970934

Crawford, S.D., Couper, M.P., \& Lamias, M.J. (2001). Web surveys. Perceptions of burden. Social Science Computer Review, 19(2), 146-162. DOI: http://dx.doi.org/10.1177/089443930101900202

Crawford, S. D., McClain, C. A., O’Brien, S., \& Nelson, T. F. (2013, May). Examining the feasibility of SMS as a contact mode for a college student survey. Paper presented at the AAPOR Annual Conference, Boston, USA.

de Bruijne, M., \& Wijnant, A. (2013). Comparing survey results obtained via mobile devices and computers: An experiment with a mobile web survey on a heterogeneous group of mobile devices versus a computer-assisted web survey. Social Science Computer Review, 31(4), 482-504. DOI: http://dx.doi. org/10.1177/0894439313483976*

Galesic, M. (2006). Dropouts on the web: Effects of interest and burden experienced during an online survey. Journal of Official Statistics, 22(2), 313-328.

Galesic, M., \& Bosnjak, M. (2009). Effects of questionnaire length on participation and indicators of response quality in a web survey. Public Opinion Quarterly, 73, 349-360. DOI: http://dx.doi.org/10.1093/poq/nfp031

Gnambs, T. (2013). The elusive general factor of personality: The acquaintance effect. European Journal of Personality, 27, 507-520. DOI: http://dx.doi. org/10.1002/per.1933 
Göritz, A. S. (2006). Incentives in web studies: Methodological issues and a review. International Journal of Internet Science, 1(1), 58-70.

Gummer, T., \& Roßmann, J. (2014). Explaining interview duration in web surveys: A multilevel approach. Social Science Computer Review, published online 21 May 2014. DOI: http://dx.doi.org/10.1177/0894439314533479

Johnson, A., Kelly, F., \& Stevens, S. (2012, March). Modular survey design for mobile devices. Paper presented at the CASRO Online Research Conference, Las Vegas, USA.

Jue, A. (2012). Participation of mobile users in traditional online studies. White paper. Fresno, CA: Decipher.

Jue, A., \& Luck, K. (2014). Update: Participation of mobile users in online surveys. Decipher White Paper. Retrieved from https://www.decipherinc. com/n/uploads/images/pages/Decipher_Mobile_Research_White_Paper_ Update.pdf.

Kelly, F., Johnson, A., \& Stevens, S. (2013, March). 'Bite-sized chunks'- mobile and CAWI parallel proposal. Paper presented at the Online Research Conference, San-Francisco, USA.

Kinesis Survey Technologies. (2013). Kinesis Whitepaper - Online Survey Statistics from the Mobile Future. Retrieved from http://www.kinesissurvey.com/wp-content/uploads/2013/10/UPDATED-with-Q3-2013-DataMobile-whitepaper.pdf

Lattery, K., Park Bartolone, G., \& Saunders, T. (2013, March). Optimizing surveys for smartphones: Maximizing response rates while minimizing bias. Paper presented at the CASRO Online Research Conference, San Francisco, USA.*

Link, M. W., Murphy, J., Schober, M. F., Buskirk,T. D., Hunter Childs, J., \& Tesfaye, C. L. (2014). Mobile technologies for conducting, augmenting and potentially replacing surveys: Report of the AAPOR task force on emerging technologies in public opinion research. Retrieved from http://www.aapor. org/Mobile_Technologies_Task_Force_Report.htm. DOI: http://dx.doi. org/10.1093/poq/nfu054

Lipsey, M. W., \& Wilson, D. B. (2001). Practical meta-analysis. Thousand Oaks, CA: Sage.

Mavletova, A. (2013). Data quality in PC and mobile web surveys. Social Science Computer Review, 31(6), 725-743. DOI: http://dx.doi. org/10.1177/0894439313485201*

Mavletova, A., \& Couper, M.P. (2013). Sensitive topics in PC web and mobile web surveys. Survey Research Methods, 7(3), 191-205.*

Mavletova, A., \& Couper, M. P. (2014a). Mobile web survey design: Scrolling versus paging, SMS versus e-mail invitations. Journal of Survey Statistics and Methodology, 2(4), 498-518. DOI: http://dx.doi.org/10.1093/jssam/ smu015*

Mavletova, A., \& Couper, M.P. (2014b). Grouping of items in mobile web questionnaires. Field Methods, forthcoming.* 
Maxl, E., Haring, W., Tarkus, A., Altenstrasser, M., \& Dolinar, M. (2010). Effects of mobile web survey invitation modes on non-response. International Journal of Mobile Marketing, 5(1), 5-14.

McClain, C., \& Crawford, S. D. (2013, May). Grid formats, data quality, and mobile device use: A questionnaire design approach. Paper presented the AAPOR Annual Conference, Boston, USA.

McGeeney, K., \& Marlar, J. (2013, May). Mobile browser web surveys: Testing response rates, data quality, and best practices. Paper presented at the AAPOR Annual Conference, Boston, USA.*

Pearson, C. (2012, May). Devices used to access surveys are changing rapidly are you prepared? Paper presented at the CASRO Technology Conference, New York, USA.*

Peterson, G., Mechling, J., LaFrance, J., Swinehart, J., \& Ham, G. (2013, March). Solving the unintentional mobile challenge. Paper presented at the CASRO Online Research Conference, San Francisco, USA.*

Peytchev, A. (2009). Survey breakoff. Public Opinion Quarterly, 73(1), 74-97. DOI: http://dx.doi.org/10.1093/poq/nfp014

Pingatore, G., \& Seldin, D. (2011). Five things about mobile data collection. ESOMAR. Retrieved from http://rwconnect.esomar.org/5-things-aboutmobile-data-collection

Siluk, L., Johnson, E. P., \& Tarraf, S. (2013, March). Cyborgs vs. monsters: Assembling modular surveys to create complete datasets. Paper presented at the Online Research Conference, San Francisco, USA.

Stapleton, C.E. (2013). The smartphone way to collect survey data. Survey Practice, $6(2) .^{*}$

Toepoel, V., \& Lugtig, P. (2014). What happens if you offer a mobile option to your web panel? Evidence from a probability-based panel of internet users. Social Science Computer Review, 32(4), 544-560. DOI: http://dx.doi. org/10.1177/0894439313510482*

Viechtbauer, W. (2010). Conducting meta-analyses in $\mathrm{R}$ with the metaphor package. Journal of Statistical Software, 36(3). Retrieved from http://cran. r-project.org/web/packages/metafor/vignettes/metafor.pdf

Viechtbauer, W., \& Cheung, W. (2010). Outlier and influencer diagnostics for meta-analysis. Research Synthesis Methods, 1, 110-125. DOI: http://dx.doi. org/10.1002/jrsm.11

Villar, A., Callegaro, M., \& Yang, Y. (2013). Where am I? A meta-analysis of experiments on the effects of progress indicators for web surveys. Social Science Computer Review, 31(6), 744-762. DOI: http://dx.doi. org/10.1177/0894439313497468

Wells, T., Bailey, J., \& Link, M. W. (2013a). Comparison of smartphone and online computer survey administration. Social Science Computer Review, 32(2), 238-255. DOI: http://dx.doi.org/10.1177/0894439313505829

Wells, T., Bailey, J., \& Link, M. W. (2013b). Filling the void: gaining a better understanding of tablet-based surveys. Survey Practice, 6(1).* 
Yan T., Conrad, F. G., Tourangeau, R., \& Couper, M. P. (2010). Should I stay or should I go: The effects of progress feedback, promised task duration, and length of questionnaire on completing web surveys. International Journal of Public Opinion Research, 23(2), 131-147. DOI: http://dx.doi.org/10.1093/ ijpor/edq046

* Article included in the meta-analysis. 